\title{
Investigation and Analysis on Social Responsibility of Medical Students Chunling Liu*
}

\author{
Chunling Liu, LuoHe Medical College, Henan Province
} 1172819778@qq.com

Keywords: Medico; Sense of social responsibility; Education; Investigation

\begin{abstract}
A questionnaire survey was carried in students from departments of clinical medicine, oral medicine, nursing, rehabilitation. The investigation was to the principle of random. Medical students' social responsibility present situation was investigated, the existing problems according to the survey were analyzed, and countermeasures and suggestions on the existing problems were proposed, and to build a social - family - school- himself four-in-one patttern of the social sense of responsibility education training mode, to realize social practice, campus culture, classroom teaching, family influence and their own efforts, such as all-round, multi-angle system of education.

Strengthening humanistic quality education in education of higher medical science is the need of medicine itself, as well as the need of new concepts of health and the transformation of medical models, and more importantly, the need to properly handle the doctor-patient relationship [1]. As the successor of medicine and the particularity of the medical profession, medical students should not only learn simple knowledge and skills, but also have more pursuits to achieve a wider sense of learning and education. However, at present, the tension between doctors and patients and the existence of medical ethics are very urgent. Therefore, it is urgent to take education measures to ease the social responsibility of medical students, so as to improve the sense of responsibility of medical students. This topic to the study of contemporary medical students education of social responsibility, through the analysis of the status quo of contemporary medical students' social responsibility, to find the cause of contemporary medical students lack of social responsibility, and put forward effective countermeasures, for college education of socialism needs qualified medical personnel to provide feasible theory basis.
\end{abstract}

\section{The Importance of Social Responsibility Education for Medical Students.}

The ultimate goal of education is to make college students feel responsible for themselves, their families and others through education activities. The sense of responsibility to themselves reflects the mental health of college students, which requires them to evaluate themselves correctly, identify their strengths and weaknesses, define their own development direction, treat others and handle affairs objectively, and bear the consequences of their behaviors bravely. The sense of responsibility to the family reflects the sense of responsibility that college students have towards their relatives or spouses. Family responsibility is built on the basis of self-responsibility. You can only be responsible to your family if you are responsible to yourself first. The sense of responsibility towards others embodies the quality of responsibility towards others, society and the country. Responsibility to others consists of two parts. On the one hand, it refers to the behavior that college students can recognize the fact of being interdependent and closely connected with others when interacting with friends, classmates and social personnel, so as to conduct exchanges and communication on an equal footing. On the other hand, it means that medical students can correctly handle the relationship between personal interests and collective interests in social life. They should keep a clear mind at critical moments, attach importance to the overall situation and stay away from individuals who have too much private interests. The cultivation of social responsibility of medical students is also conducive to enhancing their national self-esteem and sense of collective honor $[2,3]$. 


\section{Objects and Methods.}

A questionnaire survey was conducted among some students majoring in clinical, oral, nursing and rehabilitation, Mainly investigate the social responsibility consciousness of medical students, In the course of the survey, questionnaires and student interviews were distributed randomly and anonymously, avoiding the influence of subjective factors on the survey results and ensuring the objectivity and authenticity of the questionnaire. In addition, these data are analyzed and compared to grasp the essence of the problem and find the countermeasures to solve the related problems.

\section{Investigation and Analysis on the Current Situation of Social Responsibility of Medical Students.}

Positive aspect.

Most contemporary college students have a sense of justice, are willing to serve the society, are willing to reflect their own value through labor, and finally devote themselves to the construction of the country. In the face of bad atmosphere, it has a certain resistance effect, showing the elegant demeanor of college students everywhere. Our college students participate in community free consultation, environmental protection, oral health care and other social practice activities are beautiful scenery line of luohe city. These college students with their hard work, warm and thoughtful service, meticulous work, for students, teachers and citizens of luohe city.

Absence.

Always be self-centered and never change your mind. When personal interests conflict with collective interests, they only emphasize personal interests and lack the spirit of dedication to the society and the collective. In terms of employment, most of the students choose the big cities along the southern coast and are unwilling to return to their hometowns for service, which is greatly detrimental to the talent storage. In the survey, it is found that college students always measure whether the work is beneficial to them and the social atmosphere is full when they finish a certain job. Because a few university students enter the university, did not carry on the reasonable plan to oneself, appear truancy, absenteeism and so on the phenomenon. In the survey, it was also found that the number of absenteeism in the higher grades was higher than that in the lower grades, that students with good family financial conditions were more likely to be absent from school than those with financial difficulties, and that boys were more likely to be absent from school than girls. However, after the investigation, it was found that some students were not interested in some courses, and some of them liked to play online games and were very dependent on the Internet, which eventually led to failing exams and even dropping out of school.

\section{Countermeasures and Suggestions on Social Responsibility Education for Medical Students.}

The cultivation of college students' social responsibility requires the cooperation of colleges, families and society[4, 5]. Only when schools, families and society cooperate with each other and form the synergy of education in ideology and politics can college students develop their sense of social responsibility.

Optimize the social environment.

Society is the objective of student's growth, the external environment, students' learning and life is not affected by the surrounding environment, and although college students' values education adapt to the social development has made certain achievements, but there is also a collective responsibility decline, the phenomenon such as morality, we cultivate college students' social responsibility should establish the concept of moral education, build a kind of positive value orientation and guide public opinion[6]. It is found that the cultivation of social responsibility of medical students is a long-term and complex education training process, which requires clear division of labor and full cooperation from all aspects.

Play the role of school education.

Develop the function of university education to ideological and political theory class is given 
priority to, with social practice, campus culture construction for education carrier, through the play to the adjustment of the campus culture in colleges and universities, educational functions such as orientation, incentive and specification, create teaching for the college students' sense of social responsibility to cultivate good school atmosphere, play a role of the main schools to cultivate social responsibility[7].

We will improve the construction of ideological and political courses and continue to strengthen social responsibility. University stage is an important period for students to grow up and become talented, and its three views are in the formation and development stage. Although their thoughts, psychology, social cognition and moral consciousness have certain development in this period, they lack life experience, lack comprehensive understanding of the society, lack of maturity of thought, and are out of touch with the society.

We will strengthen the construction of the faculty, change the concept of running schools, change the evaluation system for students, and enhance the cultivation of social responsibility for college students. By improving the professional level and moral level of ideological and political theory teachers, a high-quality ideological and political education team will be built. Besides guaranteeing the basic teaching, the school should also hold class meetings, lectures and activities centering on the goal of cultivating college students' social responsibility.

Build a positive campus culture. Enrich college students' sense of social responsibility through various ways and channels and enhance their sense of responsibility. College students spend most of their time on campus. A good style of study, examination and noble quality are conducive to the cultivation of college students' moral values and play an irreplaceable role in the formation of college students' social responsibility[8]. First, through various festivals, students can strengthen the spirit of collectivism and patriotism. It can also publicize the content of college students' social responsibility through campus network, campus radio, publicity column and other forms [9]. Finally, strengthen the sense of responsibility. In education, psychological education and adult education are added to enable students to realize how to live independently, how to assume responsibilities independently, increase students' sense of pride and mission, gradually get rid of dependence on their parents, have the courage to face responsibilities and take the initiative to shoulder responsibilities.

Highlight family education.

Parents are the first teachers of children. Parents' words and deeds, education way and family environment have a vital influence on the formation of children's world view, outlook on life and values. It is very important to cultivate the values of young people. Good family style tutor plays a promoting role in the cultivation of young people's values[10]. Therefore, we should pay full attention to the demonstration role of family education and lay a solid foundation for school education. Parents not only require their children to be able to do things, but also to be able to be a human being. Moral education and intellectual education education should promote and complement each other. Only when moral education and intellectual education develop together will the healthy growth of children be promoted.

Strengthening yourself education is key.

Improve college students' sense of social responsibility. Translate the sense of responsibility into practical action, so as not to be absent from school, cheating, breaking the environment. Strengthen your own practical actions. College students should start from small things, never waste food, water, electricity and so on, and then rise to the protection of public property. They should be polite to people, respect the old and love the young, take the initiative to assume social responsibilities, and constantly improve their sense of social responsibility. Guide your outlook on life, world view and values with correct theories. In the process of understanding and reforming the world, we have formed a strong sense of social responsibility, and have the courage to bear our own social responsibilities [11].

\section{References}

[1] Y. Zeng: Practical Preventive Medicine, (2008)No. 15, P. 253-255. (In Chinese) 
[2] F. Liu and Y. Song: Leading Journal of Ideological \& Theoretical Education, (2014)No. 11, P. 136-139. (In Chinese)

[3] L. Xu: Ideological \& Theoretical Education, (2016)No. 04, P. 102-107. (In Chinese)

[4] X. H. Xu and L. Zhang: Journal of Kaifeng Institute of Education, (2015)No. 04, P. 179-180. (In Chinese)

[5] M. Song and M. X. Zhou: Education Review, (2014)No. 12, P. 92-94. (In Chinese)

[6] F. C. Dong: Spiritual Leaders, (2015)No. 10, P. 71-74. (In Chinese)

[7] J. J. Yu: China Adult Education, (2013)No. 21, P. 75-77. (In Chinese)

[8] C. L. Liu, L. L. Zhao and X. Yang: China Continuing Medical Education, (2015)No. 13, P. 13-14. (In Chinese)

[9] Y. L. Hang: Journal of National Academy of Education Administration, (2015)No. 12, P. 41-45. [1] Y. Zeng: Practical Preventive Medicine, (2008)No. 15, P. 253-255. (In Chinese)

[10] J. Zhang: Journal of Weinan Normal University, (2015)No. 30, P. 85-89. (In Chinese)

[11]X. M. Hou: Journal of Chinese Youth Social Science , Vol. 36(2017)No. 02, P. 99-103. (In Chinese) 